\title{
Assessing entrepreneurial ecosystems through a strategic value network approach: evidence from the San Francisco Area
}

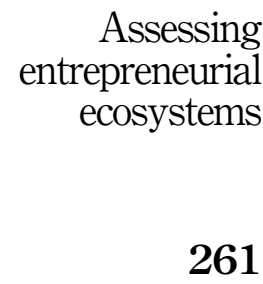

Received 3 May 2019 Revised 12 October 2020 Accepted 11 January 2021

\begin{abstract}
Purpose - The purpose of this article is to develop a model to assess entrepreneurial ecosystems. Specifically, the authors examine how to measure value creation and value capture mechanisms from a single participant's perspective and at the ecosystem level through a strategic value network-based approach.

Design/methodology/approach - Building on extant research on strategic networks, value networks and business models and leveraging a qualitative survey, the authors develop and test an assessment tool to measure value creation and capture within the entrepreneurial ecosystem of the San Francisco Bay Area.

Findings - The authors show that value-based measures on entrepreneurial ecosystems provide a systemic approach to assess how ecosystems operate, which can guide policymakers, entrepreneurs and all the other stakeholders of entrepreneurial ecosystems in their strategic decision-making process.

Originality/value - The authors provide an original model grounded in the strategic management and entrepreneurship literature for entrepreneurial ecosystems' assessment as few studies have done before. Besides, the authors provide an illustrative attempt to show how to empirically apply the original model by assessing the San Francisco Bay Area's entrepreneurial ecosystem.
\end{abstract}

Keywords Entrepreneurial ecosystems, Value creation, Value capture, Business model, Strategic networks, Value networks, Ecosystems

Paper type Research paper

\section{Introduction}

You cannot manage what you cannot measure. (Peter Drucker)

In this study, we explored research stemming from the strategy and entrepreneurship literature to the extent of providing a systemic approach on how to assess entrepreneurial ecosystems. More specifically, we developed an original framework for entrepreneurial ecosystems' assessment based on the notions of value creation and value capture mechanisms and leveraging extant research on strategic and value networks.

Entrepreneurial ecosystems are peculiar systems of interdependent actors and relations directly or indirectly supporting the creation and growth of new ventures (Cavallo et al., 2019a). Both leading political institutions and scholars show a growing interest in a broader and systemic view of entrepreneurship, recognizing the relevance of a supportive environment for new ventures and entrepreneurs (Shane and Venkataraman 2000; Acs et al., 2014). The rationale to explain the increasing attention on entrepreneurial ecosystems from both scholars and practitioners, especially during the economic crisis period [1], dominated by a scarcity of

The authors would like to thank the editors and anonymous reviewers, who helped significantly in enhancing the study's contributions as a result of the revision process. The authors also thank Paolo Zucchi for his support in this research. The authors alone are responsible in case of any errors.

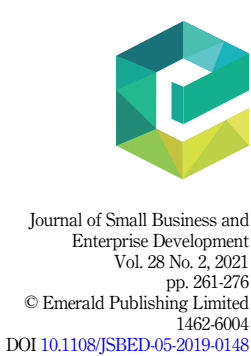


JSBED

28,2

262

resources, is the Aristotelian "The Whole is Greater than the Sum of its Parts". This assumption had already found application among various research fields, such as strategic management research, as the bases of the modern concept of synergy or alliance, and thus more recently in entrepreneurship through the entrepreneurial ecosystem construct. However, considering the wide variety of actors involved in the entrepreneurial process, policymakers struggle to identify the key action points and support the necessary measures to create and nurture entrepreneurship (Jung et al., 2017). The headline cited above is a very famous quote in the business world, often attributed to Peter Drucker, which stresses the relevance of adopting a structured and measure-based approach in management. Firms have been taking these words very seriously over the years until, for instance, to the latest data science emergence to support managerial and entrepreneurial decision-making with measures and data. However, many complexities arise when we move from organizational (or firm level) to interorganizational (or ecosystem level) analysis. There is a need for models and systemic approaches toward measuring entrepreneurial ecosystems at the interorganizational level.

To date, there has been a significant amount of research dealing with the identification of the main entrepreneurial ecosystems' actors and also providing (several) representative frameworks (e.g. Isenberg, 2010, 2011; Cohen, 2006). Other studies focus on entrepreneurial ecosystem definition, the roots of entrepreneurial ecosystems in terms of its antecedents in the literature, and review the current knowledge we possess on entrepreneurial ecosystems (Cavallo et al., 2019a; Alvedalen and Boschma, 2017; Stam, 2015). Major attention has been dedicated to the entrepreneurial ecosystems and their key attributes (Roundy et al., 2017) or governance structures (Colombo et al., 2019). However, to the best of our knowledge, despite the abundant research produced by scholars recently, we still possess limited knowledge on how to assess an entrepreneurial ecosystem (Cavallo et al., 2019a; Stam, 2015; Bell-Masterson and Dane, 2015). This study aims at filling this gap by answering the following research question: how to assess entrepreneurial ecosystems and gain a comprehensive understanding of value creation and capture process within entrepreneurial ecosystems?

Answering this question is important as it helps to address the systemic nature of entrepreneurship. Through studying how to assess and measure an entrepreneurial ecosystem, we make at least two contributions to the literature. First, building on extant constructs and strategic and value network approaches, we provide the strategic value network model as an original framework grounded in strategic management for entrepreneurial ecosystems assessment. Second, our study provides a first illustrative application of such a model, based on a qualitative survey, in the context of a well-known and successful case of entrepreneurial ecosystems, i.e. the San Francisco Bay Area.

\section{Literature review}

\subsection{Entrepreneurial ecosystem research}

Entrepreneurship research is gradually moving from a major emphasis and focus on individual perspective toward a systemic view (Shane and Venkataraman, 2000). The roots of such a shift in the locus of investigation are multiple. Scholars argue, for instance, that the entrepreneurial process is becoming more collective involving different actors, as consequences of affordances are freed by digital technologies (Nambisan, 2017; Autio et al., 2018). Others argue that globalization is a key factor in creating interdependencies and interconnections on a large scale in entrepreneurship. This explains and justifies the broad interests of scholars on entrepreneurial ecosystems. The entrepreneurial ecosystem can be defined as "a set of interdependent actors and factors coordinated in such a way that they enable productive entrepreneurship within a particular territory" (Stam, 2015, p. 5). Across the years, scholars seem to embrace the term ecosystem over a network as a powerful way to conceptualize networks (Iansiti and Levien, 2004), and Stam's (2015) definition of entrepreneurial ecosystem has been endorsed in the literature for its comprehensive nature 
(e.g., Acs et al., 2017). Building an entrepreneurial ecosystem is a topic already examined in the literature and valuable in particular for policymakers (Feldman et al., 2005; Isenberg, 2010; Pitelis, 2012: Hahn et al., 2019). Cohen (2006) explores how components of the formal and informal network, physical infrastructure and culture within a community could contribute to a sustainable entrepreneurial ecosystem. Isenberg (2010) points out the main dimensions of the entrepreneurial ecosystem and includes interesting suggestions direct to policymakers. This vision goes beyond the company value chain and opens to a set of elements that must be managed holistically to sustain the ecosystem (Isenberg, 2010; Stam, 2015; Cavallo et al., 2019a). There were also attempts to present a static view of the entrepreneurial ecosystem as a whole, with a systematic approach (e.g. Neck et al., 2004). More recently, scholars argue about the relevance of a dynamic view (Haarhaus et al., 2020), following the system dynamics method (Cavallo et al., 2019a). Research studies assert that economic activities are changing from dominantly stand-alone to networked, and new perspectives are needed to study these networked relationships (Anggraeni et al., 2007; Secundo et al., 2020).

To sum up, research on entrepreneurial ecosystem is witnessing an exponential growth of contributions; however, the debate is still ongoing, especially in need of theorizing (Cavallo et al., 2020; Stam, 2015). In particular, scholars discuss how to measure the entrepreneurial ecosystem and gain a comprehensive understanding (Spigel, 2017; Stam, 2015).

In this study, we will analyze the entrepreneurial ecosystem considering the system of exchanges and transactions among firms as part of the network. To do that, we will base our research on the strategic network (Gulati, 1995) and value network (Alle, 2000) constructs. Following, we further develop this point by first presenting a review of such constructs, and then we propose an original model to support the strategic assessment of entrepreneurial ecosystems.

\subsection{The strategic network}

The link between networks and strategy was grasped only in the middle 80 s because the two concepts were coined in completely different fields. However, the attention on this link raised considerably year by year, enriching the literature with a substantial amount of studies (e.g. Jarillo, 1988). For a long period of time, researchers have considered firms as completely autonomous entities, trying to gather a competitive advantage (Porter, 1980, 1996). However, due to the continuous increase of exchanges and relationships between organizations (Granovetter, 1985; Sassanelli et al., 2018), the entire network of organizations started to gain increasing attention (Hoang and Antoncic, 2002, 2003; Holm et al., 1999; Moore, 1993). While referring to strategic networks, many researchers had focused on alliances between firms and, especially, on learning alliances, in which the primary objective of the partners is to learn from each other (Baum et al., 2000; Garcia-Pont and Nohria, 2002; Gulati, 1995, 1998; Khanna et al., 1998; Mody, 1993). These alliance relationships between firms generate a set of resources jointly owned by the partners called "social capital" (Walker et al., 1997). This capital is a critical variable and is defined by Burt (1992) as the final arbiter of competitive advantage. Moreover, a study made by Shan, Walker and Kogut (1997) found that the number of a firm's collaborative relationship is positively related to its innovation output. Several studies focus on networks' structure and how it influences the firm (Baum et al., 2000). Gulati et al. (2000) reviewed a wide set of literature and highlighted some key static features in a network in order to draw a model, introducing concepts like focal firms, firm ties, structural holes and structural equivalences. Gulati et al. (2000) also try to outline the challenging topic of dynamic behaviors among the network, bringing together the studies on lock-in and lockout effects (Baum et al., 2000) that analyze the consequences of being in an exchange relationship with other companies and on learning races (Baum et al., 2000; Cohen and Levinthal, 1990; Khanna et al., 1998; Mody, 1993) that look at possible opportunistic behaviors due to a wrong balance between common and private benefits. 
JSBED 28,2
Despite the valuable extant contributions, the literature is limited on defining the nature of the exchanges between organizations and struggles in linking a firm's strategic choice with the resulting value generated toward more complex, multi-level models of strategy (Borch and Arthur, 1995). To cope with this issue, we believe value-based analysis and business model construct may come to aid.

\subsection{Value networks, business models and entrepreneurial ecosystems}

Strategy research highlights the relevance of intangible exchanges between firms, as they constitute the $50-70 \%$ of the whole exchanges between different organizations nowadays (Wild, 2009). As regards, Verna Allee (2000b) recommended an evolution of the traditional business frameworks to an expanded view of potential value domains made of exchanges of "knowledge" and "intangible" other than normal goods. A value network can be defined as any web of relationships generating tangible and intangible value based on complex dynamic exchanges between two or more network participants, such as individuals, groups or organizations (Allee, 2000b). The definition itself paves the way for a more straightforward approach in linking network analysis and organizational performance, thanks to the expanded view of network analysis.

Peppard and Rylander (2006) argue that this approach drives organizations to focus on the value-creating system itself, within which different economic actors (e.g., suppliers, partners, Allies and customers) work together to coproduce value strategically. The value-based approach is grounded on the assumption that business organizations must be considered as a "living system" as they are complex and messy systems, and must be evaluated based on relationships between them and "exchanges", the molecular level of economic exchange (Allee, 2008). Allee gives a new definition of intangibles strictly related to value creation by arguing that other than considering intangibles as assets, they must be considered negotiable forms of value and deliverables in the process of value conversion from nonfinancial to financial value (Allee, 2008). The analysis put forward by Allee (2008) proposes a more systemic way to analyze, evaluate and improve the performances of a network based on four different phases: value mapping, exchange analysis, impact analysis and value creation analysis (Allee, 2000a, 2000b, 2008). Their intangible exchanges outnumber key tangible ones by two to one, making a traditional analysis based on money and goods revenues obsolete and misleading, as it is possible to verify in the maps below.

Value network analysis is oriented toward a complex adaptive system view of value creation (Allee and Schwabe, 2009). It can be fruitfully connected with the growingly relevant concepts and constructs of the business model and the entrepreneurial ecosystem.

The relationship between the concept of business model and value network is grounded in the extant literature on strategic management (Jocevski et al., 2020).

For instance, Shafer et al. (2005) argue that a business model represents a firm's underlying core logic and strategic choices for creating and capturing value within a value network. Thus, they emphasize that value creation and value capture occur within a value network, and the role a firm chooses to play within its network is an important element of its business model. Also, Ghezzi (2013) proposes that value networks are a system of interconnected and interplaying business models of different firms operating in the industry and involved in value exchanges. In general terms, the business model has often been conceptualized as a complex system of interdependent activities performed by the firm and its partners, with transaction mechanisms that link these activities (Massa and Tucci, 2013; Cavallo et al., 2019b).

In a similar vein, entrepreneurial ecosystems are a known example of complex and evolving systems leading to new ventures' creation and growth. Despite a clear closeness between business model and entrepreneurial ecosystem, only recent scholars consider the 
connection between these two relevant research constructs. According to Autio et al. (2018), digital technologies and relative affordances increase chances for business model innovation in entrepreneurial ecosystems, enabling fast experimentations and prototyping. We deem that there is room to further explore such a connection from a value perspective. Specifically, measuring entrepreneurial ecosystems' value creation and capture process requires a new set of assumptions due to the presence and exchange of tangible and especially intangible assets, as central in the current knowledge-based economy (Edvinsson, 1997; Etzkowitz, 2003). Concluding, we will leverage on strategic network, value network and business model constructs and approaches for building a new method to measure entrepreneurial ecosystems. We develop this point further in the following section.

\section{An original model for entrepreneurial ecosystem assessment}

Based on the combination of strategic network and value network constructs and approaches, we introduce a new model for assessing entrepreneurial ecosystems. The purpose of our original model is to evaluate an entrepreneurial ecosystem, highlighting the impact of the network on participants and vice-versa.

The strategic value network model (Figure 1) is structured into different phases of analysis: strategic value map, network analysis and strategic value analysis. A detailed description of each phase is given below.

\subsection{Strategic value map}

The first step to understand how an ecosystem is structured as follows, who are the participants of the network, how they are tied and which exchanges are placed among them. This can be done by leveraging on exchange map and ties map that combined represent the so-called strategic value map. The exchange map depicts an ecosystem's exchange (both tangible and intangible), allowing us to understand the transactions happening in the network at an atomistic level. When illustrating a wide ecosystem, it is noteworthy to remark that it is preferable to split the exchange map into a tangible map and an intangible map.

The exchange map should be complemented by a ties map, which represents the linkages graphically among the network participants, giving a first view of the relationships between organizations.

\subsection{Network analysis}

The network analysis is a critical phase in which the model allows to assess the ecosystem's structure and the position each player is holding in it. Drawing on strategic network theories, the network analysis included the identification of structural holes and structural equivalences. The structural hole map depicts the interruptions among firms' linkages due to situations where two or more participants within a network are connected only indirectly

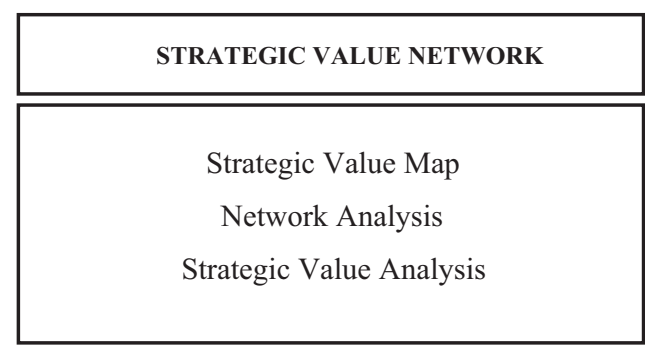

\section{Assessing entrepreneurial ecosystems}


JSBED

28,2 through a third participant. Structural holes are highly relevant for developing a healthy ecosystem since they obstruct the flow of information and exchange: the more structural holes present in the map, the less efficient the ecosystem will be (Coleman, 1988).

The structural equivalence map highlights when participants are holding a similar position within the network. Structural equivalence means conducting the same activities or having the same network of other participants. The presence of numerous structural equivalences may increase competition among redundant actors, undermining an ecosystem's health.

The network analysis also leverages value network theories while identifying the number of direct and indirect ties and the number of tangible and intangible exchanges for each network participant. This in order to get further insights into the density of the network.

The network analysis provides relevant insights into an ecosystem assessment. By analyzing density, interconnection and diversity of the network, it is possible to understand whether the ecosystem is an open system or a closed system. An open system is characterized by many indirect ties and a resulting relevant number of structural holes. On the contrary, a closed system is featured by dense networks in which almost every participant is linked with each other and constituted, for the most part, of direct linkages. Furthermore, thorough the network analysis, it is possible to identify one (or more) focal participant. A focal participant is (1) standing in a central position within the network; (2) linked to almost all the other participants and (3) holding the main source of value for the system.

\subsection{Strategic value analysis}

Once completed the network analysis, our model, drawing on business model theories, proposes measuring value capture and value generation mechanisms. The outcome will be a detailed illustration of the network's flows by selected participants focusing on the value capture ability both on participant and ecosystem level. The strategic value analysis main steps are described as follows. The first step is to draw an input and output map where each participant's inputs and outputs are displayed separately to enhance a specific and detailed analysis. The second step included input and output analysis. The input analysis evaluates the nature of the input and the impact that each of the collaborative players within the ecosystem has on analyzing participants' business activities. The analysis aims to assess the total value achieved by being part of the ecosystem by calculating the sum of each input value. The impact is evaluated through a five-point Likert scale weighted on consensus. The output analysis assesses the resource spent by the analyzed participant for the generation of beneficial value for the surrounding ecosystem, focusing on both tangible and intangible resources necessary for the outputs exchange. The sum of all the output values of each company returns the total value-added costs bear in the network activity's participation. The value-added cost level is evaluated through a five-point Likert scale weighted on consensus. The third step is the value capture analysis both at the participant and ecosystem level. The participant-level capture value represents the ability to capture value from an analyzed participant's ecosystem, a key characteristic of an ecosystem assessment. Similarly, the value capture at the ecosystem level represents the ecosystems' ability to capture value from the participants' interactions and exchanges. Following the detailed formula to calculate the value capture at the participant level (1) and ecosystem level (2),

$$
\sum_{i=1}^{n} \operatorname{input}\left(i_{k}\right)-\sum_{j=1}^{m} \operatorname{output}\left(j_{k}\right)=\text { value capture }_{k}
$$




$$
\begin{aligned}
& i_{k}=\text { input } i \text { of participant } k, \\
& j_{k}=\text { output } j \text { of participant } k, \\
& n=\text { total \# of inputs of a participant } k, \\
& m=\text { total \# of outputs of a participant } k \text { and } \\
& k=\text { each participant. } \\
& \qquad \sum_{i}^{n}(\text { impact }-\operatorname{cost})_{i}=\text { ecosystem value capture } \\
& i=\text { exchange } i \text { and } \\
& n=\text { total \# of exchanges. }
\end{aligned}
$$

\author{
Assessing \\ entrepreneurial \\ ecosystems

It is noteworthy to highlight that in multiple answers on a single exchange, the research model leverages on consensus measure. The consensus is a value between 0 and 1 representing an adjustment necessary to combine with parametric instruments, different qualitative opinions gathered, for example, with a Likert scale. A close equivalent to a consensus might be "the collective opinion of a group"; in fact, it allows to give a value representing the majority of the opinions, generating a consensus among them (Ghezzi et al., 2015). Formula (3) necessary for the calculation of the consensus value comes from Tastle and Wierman (2007), and it is illustrated below:

$$
\text { Consensus }=1+\sum_{i=1}^{n} p_{i} * \log _{2}\left(1-\frac{\left|X_{i}-\mu_{x}\right|}{d_{x}}\right)
$$

$$
\begin{aligned}
& p_{i}=\text { probability of outcome } X_{i}, \\
& \mu_{x}=\text { mean of } X \\
& d_{x}=X_{\max }-X_{\min } .
\end{aligned}
$$

\section{Method}

\subsection{Research design}

This section presents the research design and process that lead to the first illustrative and empirical attempt to apply our proposed model for entrepreneurial ecosystems' assessment.

To test our framework, we studied each of the critical groups belonging to the ecosystem, such as startups, venture capital funds, business angels, banks, venture incubators and accelerators, coworking spaces, universities and consulting firms. We have selected a convenience sample of 18 participants among the key actors and experts in the local entrepreneurial ecosystem in San Francisco. A qualitative survey was carried out during an interview (Jansen, 2010) with the selected participants involved, deemed as a valuable research technique in entrepreneurship (e.g. Sandberg, 2003) to both systematically collect data from the participants while building a reliable perception of the dynamics going on within the reference ecosystem.

To further reinforce our method, information gathered through the qualitative survey has been validated through a thorough analysis of secondary sources, participant observation at local events relevant to the ecosystem and remote ex-post observation of the data collected. 
JSBED

28,2

268

\subsection{Data gathering}

The data gathering process started with defining the subcategories of participants through an analysis of secondary sources. Consequently, we focused on the dynamics leading the network and the value exchanged among roles. The interview process constituted the main means employed to achieve this objective: interviews consisted of semistructured phone and face-to-face interviews with relevant actors and well-known experts of San Francisco's entrepreneurial ecosystem. Interview questions were adapted from some key issues identified by analyzing the extant literature on entrepreneurial ecosystems, although some new concepts were introduced to better match the research objectives (Yin, 2009). To ensure consistency and comparability among different interviews, the research protocol's main questions were common for all interviewees. However, separate questions were customized to the respondent's specific roles and follow-up questions on the emergent issues. The interviews lasted $43 \mathrm{~min}$ on average, and the responses from interviewees were recorded and transcribed. Then, a within-case data analysis was carried out. Informants were later recontacted by phone, after a first exchange-map development, in order to gather evaluations on impacts on performances and value-added costs. Lastly, the case descriptions and results were reviewed and confirmed by the interviewees to mend any error or bias and ultimately ensure the correctness of interpretations.

As the validity and reliability of a qualitative study rest heavily on the correctness of the interviewees' information and can be assured by using multiple sources (Yin, 2009), several secondary sources of evidence were employed to supplement and triangulate the data collected through the qualitative survey. Also, participant observation has been employed (between May and August 2015) to confirm and deep dive into the network dynamics resulting from the qualitative survey. Participant observation is a data collection method typically used for qualitative research that aims at gaining a close and intimate familiarity with a determined group of individuals and their activities through an intensive involvement with people in their cultural environment (Burawoy, 1998). Such on-field experience awarded the research team with the possibility to accelerate the learning process and get valuable insights into the ecosystem's dynamics put into practice, particularly valuable when researching the field of entrepreneurship (e.g. Anderson and Jack, 2002).

The data collected was finally verified and finalized through remote observation. Remote observation is an observational technique that does not include the overlapping roles of researchers and an active member of the studied group. This helps to keep a cognitive detachment from the object of study, preserving the idea of "objectivity", according to experts' theories, is the most significant weakness of the qualitative approach. The data collected on-field through the qualitative survey, interviews and events were then remotely objectively analyzed and translated into a framework by a team of three independent researchers.

\section{Empirical evidence from the San Francisco Bay Area}

After having illustrated the characteristics of the evaluation strategic value network assessment model developed exhaustively, we have implemented the procedures to the San Francisco Bay area's entrepreneurial ecosystem.

In particular, we will show the results of the strategic value analysis, as the third and core phase of the strategic value network assessment model, since it incorporates the first two phases. For brevity purposes, we will show the assessment of the entrepreneurial ecosystem's focal players as participant-level analysis, i.e. startups. The same procedure has been applied to all other players, part of the entrepreneurial ecosystem, and finally collected to provide an ecosystem-level assessment. 
5.1 Participant-level value analysis: startups

This category is composite by each entrepreneurial venture headquartered in San Francisco, and being a source of high risky earnings, they constitute the tangible side of the ecosystem. The extraordinary success of the Silicon Valley area brings many talented entrepreneurs to immigrate to the Bay, establishing the highest startup density of the planet. They fully exploit the ecosystem being connected with all the other participants to gather their support services in exchange for tangible assets such as equity shares or money (see Figures 2 and 3).

Table 1 illustrates the value impacts of the ecosystem on the analyzed entity and the participant's costs for adding value to the ecosystem; these two different evaluations allow the research to calculate the value generated and the value-added costs for each participant. The numerical calculations are based on the multiple case study interviews and assessed with a Likert scale weighted on consensus.

The high number of inputs received by startups reflects the ecosystem's intrinsic nature, aiming to support entrepreneurs through a wide selection of services. Investment and mentorship programs have a high impact on performances, representing the vital nourishment and knowledge. On the contrary, bank loans represent a smaller impulse for startup business activities as they have the trade-off of onerous interests. Worthy of attention is also the other intangible exchanges constituting solid info sharing base.

Their complete tangible nature characterizes startup outputs; they represent alone almost half of the total tangible exchanges since they are the ecosystem's monetary center and have to pay for the ecosystem's ample services (see Table 2).

The sum of all the input gives us the value generated by the ecosystem (startup total value inflows $=4,091$ ), while one of the output returns the costs for participating to it (startup total value outflows $=1,763$ ). Subtracting the costs sustained by the participant to the value benefits it receives, the analysis arrives at a number representing the value captured (startup value capture $=2,328$ ). The resulting value captured by startups is positive. It may represent a favorable environment for entrepreneurs, explaining the high numbers of entrepreneurs from all over the world going to San Francisco Bay every year and starting their company.

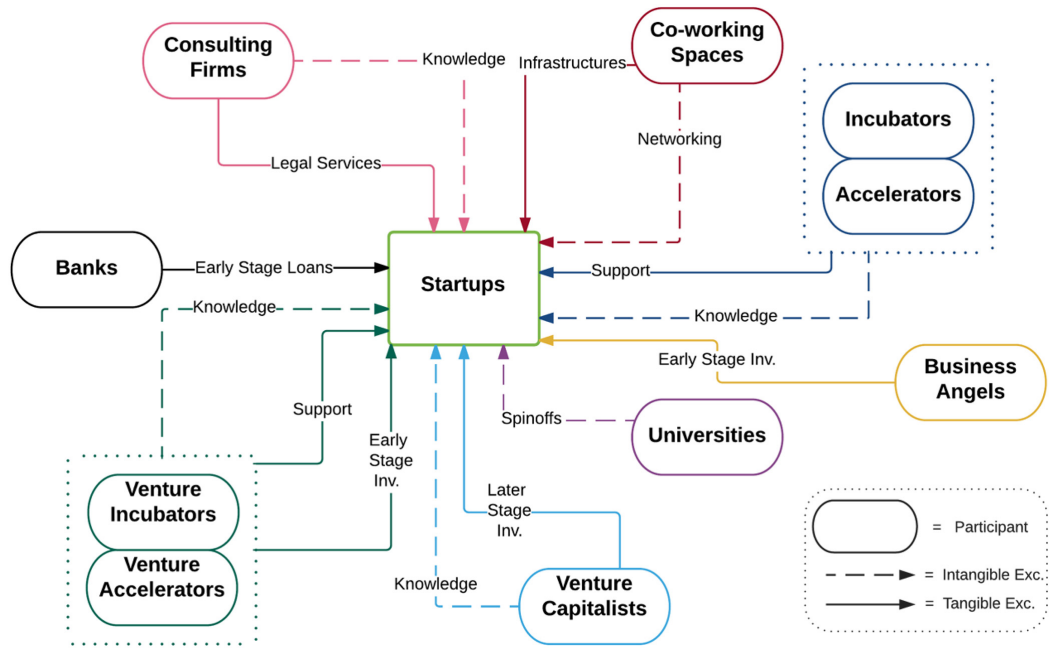

Figure 2. Startups inflows 
JSBED

28,2

270

Figure 3.

Startups outflows

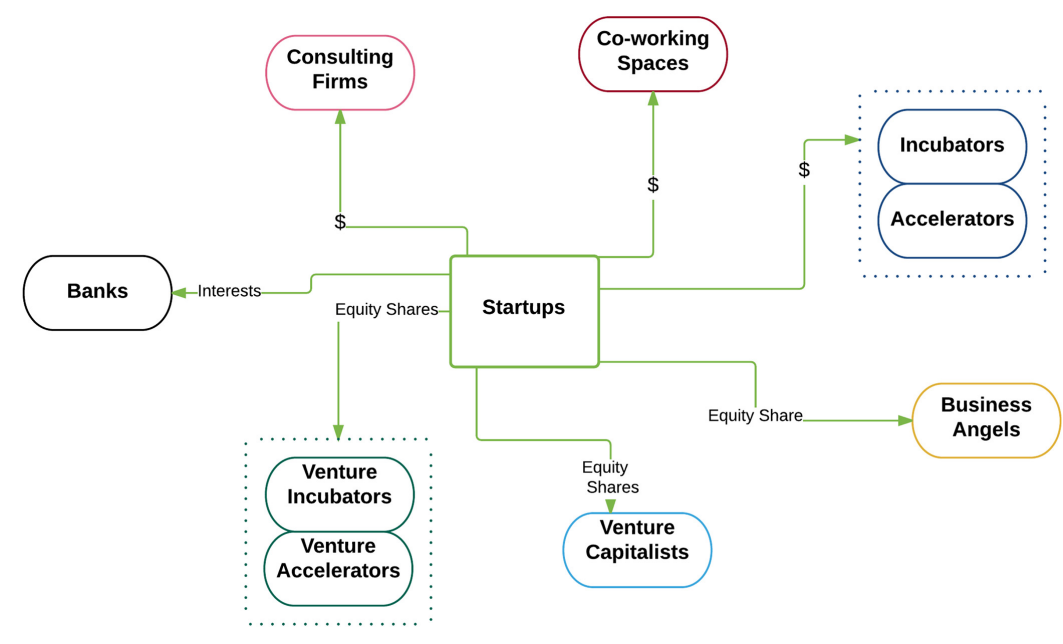

\begin{tabular}{|c|c|c|c|}
\hline Input & Origin & (T) Tangible/(I) intangible & Impact \\
\hline Legal services & Consulting firms & $\mathrm{T}$ & 3,20 \\
\hline Knowledge & Consulting firms & I & 1,69 \\
\hline Infrastructure & Coworking spaces & $\mathrm{T}$ & 3,20 \\
\hline Networking & Coworking spaces & I & 2,40 \\
\hline Support & Incubators/accelerators & $\mathrm{T}$ & 3,14 \\
\hline Knowledge & Incubators/accelerators & I & 3,00 \\
\hline Early stage inv & Business angels & $\mathrm{T}$ & 5,00 \\
\hline Spinoffs & Universities & I & 2,40 \\
\hline Later stage inv & Venture capitalists & $\mathrm{T}$ & 3,20 \\
\hline Knowledge & Venture capitalists & I & 1,69 \\
\hline Early stage inv & $\begin{array}{l}\text { Venture } \\
\text { acc./incub }\end{array}$ & $\mathrm{T}$ & 2,41 \\
\hline Support & $\begin{array}{l}\text { Venture } \\
\text { acc./incub }\end{array}$ & $\mathrm{T}$ & 5,00 \\
\hline Knowledge & $\begin{array}{l}\text { Venture } \\
\text { acc./incub }\end{array}$ & I & 2,65 \\
\hline $\begin{array}{l}\text { Early stage loans } \\
\text { startup total value inflows }\end{array}$ & Banks & $\mathrm{T}$ & $\begin{array}{r}1,93 \\
40,91\end{array}$ \\
\hline
\end{tabular}

Table 1.

Value inflows

\subsection{Ecosystem value capture analysis}

The ecosystem-level analysis is simply made through the sum of the computations of each exchange value capture at the participant level. The resulting San Francisco Bay entrepreneurial ecosystem value capture is 3,808. Therefore, the balance at the ecosystem level seems positive. This is not surprising. Entrepreneurship literature largely describes San Francisco Bay's positive and even inimitable conditions (e.g. Isenberg, 2010). The ecosystem value capture result is essential for the ecosystem's overall strategic performance assessment; a positive value indicates a healthy environment for startups.

In conclusion, the mere numerical value of 3,808 does not give, taken in absolute terms, an idea of how an ecosystem performs. We need future analysis of other entrepreneurial ecosystems to develop a proper benchmark evaluation base. Our strategic performance 


\begin{tabular}{|c|c|c|c|c|}
\hline Output & To & (T) Tangible/(I) intangible & Value added cost & Asse \\
\hline Money & Consulting firms & $\mathrm{T}$ & 1,21 & ecosystems \\
\hline Money & $\begin{array}{l}\text { Coworking } \\
\text { spaces }\end{array}$ & $\mathrm{T}$ & 1,93 & \\
\hline Money & Incubators/accelerators & $\mathrm{T}$ & 2,40 & \\
\hline Equity share & $\begin{array}{l}\text { Business } \\
\text { angels }\end{array}$ & $\mathrm{T}$ & 4,00 & 27 \\
\hline Equity share & Venture capitalists & $\mathrm{T}$ & 4,00 & \\
\hline Equity share & Venture incubators/accelerators & $\mathrm{T}$ & 2,40 & \\
\hline Interests & Banks & $\mathrm{T}$ & 1,69 & \\
\hline startup total ve & outflows & & 17,63 & Tabl \\
\hline \multicolumn{4}{|c|}{$\operatorname{Note}(\mathbf{s})$ : Impact: $1=$ very low; $2=$ low; $3=$ medium; $4=$ high and $5=$ very high } & Value outfl \\
\hline
\end{tabular}

analysis, numerically calculated in terms of tangible and intangible value creation with an innovative empirical model, is among the first academic attempts for entrepreneurial ecosystem assessment. It provides detailed insights into the strategic ecosystem dynamics and constitutes a powerful tool available for future research implementations.

\section{Implications for theory and practice}

This study explores how to assess an entrepreneurial ecosystem. A review of the literature on strategic networks, business models and value networks informed our investigation. Our study provides scholars and practitioners with an original entrepreneurial ecosystem assessment model and an illustrative example of application considering the San Francisco Bay Area.

The study is not free of limitations. First, our empirical effort is limited to a single entrepreneurial ecosystem, since our main aim was to build an assessment model leveraging on established theories stemming from strategy and entrepreneurship. We encourage future research to apply our original model on different ecosystems to ground the practical implications on accurate relative performance measures and crosscountry comparison analysis. Researchers should also consider complementing our method to pursue empirical balancing out to the interviews, for instance, by considering attitudinal measures for entrepreneurial ecosystems (see Liguori et al., 2019). Despite these limitations, the study presents value for both research and practice.

Research value is mainly connected to the strategic value network model introduced. The model is grounded in the sound literature, which few studies have tried to link before, such as strategic network, business model and value network constructs and approaches. These constructs were combined into an original assessment model that maps efficiently and holistically an entrepreneurial ecosystem, where both tangible and intangible values are relevant. Our model allows us to efficiently map ecosystems in terms of value generation and value capture performances, as few studies have done before. Academic research on the entrepreneurial ecosystem has become chaotic and redundant, featuring only a few studies that embrace systematic evidence and theoretical frameworks (Spigel and Harrison, 2018; Stam, 2015). In this study, we face this challenge, and we model the entrepreneurial ecosystem as a process of value exchange among the network's participants. The presence and the circulation of value exchanges help in explaining how entrepreneurial ecosystems evolve and transform over time, thus capturing a dynamic perspective lacking in entrepreneurial ecosystem literature (Cavallo et al., 2019a). Finally, we show that a value perspective on the entrepreneurial ecosystem provides a more systemic approach to disclose how ecosystems 
JSBED

28,2

operate. Our model could be applied to other forms of complex and dynamic systems. We hope this could serve scholars stemming from different research fields in conducting ecosystems' assessment.

Our study also offers a set of relevant applications to practice. Policymakers may find it useful to apply our study to get insights into the fundamental actors, relations and value exchanges within their entrepreneurial ecosystem of interests. Indeed, our model does not discriminate among entrepreneurial ecosystems. It can apply at different levels of analysis and territory from city to region to country level. Clearly, the smallest is the level of analysis, the easier the entrepreneurial ecosystem assessment will be in terms of empirical effort.

On the other hand, the action space of policy measures fostering entrepreneurial ecosystems at a local level may be significantly limited. Ideally, spreading the practice of measuring local entrepreneurial ecosystems (e.g. city level) and then at an higher aggregate level (e.g. country level) would constitute a systemic and pervasive approach to gain a comprehensive understanding of entrepreneurial ecosystems. This knowledge can lead to more effective and specific policy measures to sustain new venture creation and growth. Also, several implications may emerge from the firm-level analysis. For instance, entrepreneurs may find it useful to obtain information about how supportive an ecosystem is, guiding their expansion or relocation strategies. Similar considerations may apply to any entrepreneurial ecosystem stakeholders (e.g. incubators, venture capitalists, angel networks and universities), as witnessing the wide spectrum of benefits related to measuring entrepreneurial ecosystem for practice. Overall, we believe the field is still in need to further advance the understanding of entrepreneurial ecosystems in research and practice.

\section{Note}

1. We refer to the two crises of the Internet bubble (2000) and the more recent sub-prime cries (2007), which are considered among the worst economic crises in history together with the big crash (1929).

\section{References}

Acs, Z.J., Autio, E. and Szerb, L. (2014), "National systems of entrepreneurship: measurement issues and policy implications", Research Policy, Vol. 43 No. 3, pp. 476-494.

Acs, Z.J., Stam, E., Audretsch, D.B. and O'Connor, A. (2017), "The lineages of the entrepreneurial ecosystem approach”, Small Business Economics, Vol. 49 No. 1, pp. 1-10.

Allee, V. and Schwabe, O. (2009), "Measuring the impact of research networks in the EU: value networks and intellectual capital formation", Proceedings of the European Conference on Intellectual Capital, pp. 27-35.

Allee, V. (2000a), "Reconfiguring the value network", Journal of Business Strategy, Vol. 80 No. 6, p. 275, doi: 10.1049/me:20010612.

Allee, V. (2000b), "The value evolution: addressing larger implications of an intellectual capital and intangibles perspective", Journal of Intellectual Capital, Vol. 1 No. 1, pp. 17-32, doi: 10.1108/ 14691930010371627.

Allee, V. (2008), "Value network analysis and value conversion of tangible and intangible assets", Journal of Intellectual Capital, Vol. 9 No. 1, pp. 5-24.

Alvedalen, J. and Boschma, R. (2017), "A critical review of entrepreneurial ecosystem research: towards a future research agenda”, European Planning Studies, Vol. 25 No. 6, pp. 887-903.

Anderson, A.R. and Jack, S.L. (2002), "The articulation of social capital in entrepreneurial networks: a glue or a lubricant?", Entrepreneurship and Regional Development, Vol. 14 No. 3, pp. 193-210. 
Anggraeni, E., Hartigh, E. Den and Zegveld, M. (2007), Business Ecosystem as a Perspective for Studying the Relations between Firms and Their Business Networks, Veldhoven, pp. 1-28.

Autio, E., Nambisan, S., Thomas, L.D. and Wright, M. (2018), "Digital affordances, spatial affordances, and the genesis of entrepreneurial ecosystems", Strategic Entrepreneurship Journal, Vol. 12 No. 1, pp. 72-95.

Baum, J.a. C., Calabrese, T. and Silverman, B.S. (2000), "Don't go it alone: alliance network composition and startups' performance in Canadian biotechnology”, Strategic Management Journal, Vol. 21 No. 3, pp. 267-294.

Bell-Masterson, J. and Dane, S. (2015), Measuring an Entrepreneurial Ecosystem, Ewing Marion Kauffman Foundation, Kansas City, MO.

Borch, O.J. and Arthur, M.B. (1995), "Strategic networks among small firms: implications for strategy research methodology", Journal of Management Studies, Vol. 32 No. 4, pp. 419-441.

Burawoy, M. (1998), “The extended case method”, Sociological Theory, Vol. 16 No. 1, pp. 4-33.

Burt, R. (1992), Structural Holes: A New Theory of Competition, Harvard University, Harvard.

Cavallo, A., Ghezzi, A. and Balocco, R. (2019a), "Entrepreneurial ecosystem research: present debates and future directions", International Entrepreneurship and Management Journal, Vol. 15 No. 4, pp. 1291-1321.

Cavallo, A., Ghezzi, A. and Ruales Guzmán, B.V. (2019b), "Driving internationalization through business model innovation: evidences from an AgTech company", Multinational Business Review, Vol. 28 No. 2, pp. 201-220, doi: 10.1108/MBR-11-2018-0087.

Cavallo, A., Ghezzi, A. and Rossi-Lamastra, C. (2020), "Small-medium enterprises and innovative startups in entrepreneurial ecosystems: exploring an under-remarked relation", International Entrepreneurship and Management Journal. doi: 10.1007/s11365-020-00698-3.

Cohen, W. and Levinthal, D. (1990), "Absorptive capacity: a new perspective on learning and innovation”, Administrative Science Quarterly, Vol. 35 No. 1, pp. 128-152.

Cohen, B. (2006), "Sustainable valley entrepreneurial ecosystems", Business Strategy and the Environment, Vol. 15 No. 1, pp. 1-14, doi: 10.1002/bse.428.

Coleman, J.S. (1988), "Social capital in the creation of human capital", American Journal of Sociology, Vol. 94, pp. S95-S120.

Colombo, M.G., Dagnino, G.B., Lehmann, E.E. and Salmador, M. (2019), "The governance of entrepreneurial ecosystems", Small Business Economics, Vol. 52 No. 2, pp. 419-428.

Edvinsson, L. (1997), “Developing intellectual capital at Skandia”, Long Range Planning, Vol. 30 No. 3, pp. 366-373.

Etzkowitz, H. (2003), "Innovation in innovation: the triple helix of university-industry-government relations", Social Science Information, Vol. 42 No. 3, pp. 293-337.

Feldman, M., Francis, J. and Bercovitz, J. (2005), "Creating a cluster while building a firm: entrepreneurs and the formation of industrial clusters", Regional Studies, Vol. 39 No. 1, pp. 129-141, doi: 10.1080/0034340052000320888.

Garcia-Pont, C. and Nohria, N. (2002), "Local versus global mimetism: the dynamics of alliance formation in the automobile industry", Strategic Management Journal, Vol. 23 No. 4, pp. 307-321.

Ghezzi, A., Balocco, R. and Rangone, A. (2015), "A fuzzy framework assessing corporate resource management for the mobile content industry", Technological Forecasting and Social Change, Vol. 96, pp. 153-172.

Ghezzi, A. (2013), "Revisiting business strategy under discontinuity", Management Decision, Vol. 51 No. 7, pp. 1326-1358.

Granovetter, M. (1985), "Economic action and social structure: the problem of embeddedness", American Journal of Sociology, Vol. 91 No. 3, pp. 481-510. 
JSBED

28,2

Gulati, R., Nohria, N. and Zaheer, A. (2000), "Strategic networks", Strategic Management Journal, Vol. 21 No. 3, pp. 203-215.

Gulati, R. (1995), "Social structure and alliance formation Patterns: a longitudinal analysis", Administrative Science Quarterly, Vol. 40 No. 4, pp. 619-652, doi: 10.2307/2393756.

Gulati, R. (1998), “Alliances and networks”, Strategic Management Journal, Vol. 19, pp. 293-317.

Haarhaus, T., Strunk, G. and Liening, A. (2020), "Assessing the complex dynamics of entrepreneurial ecosystems: a nonstationary approach", Journal of Business Venturing Insights, Vol. 14, p. e00194.

Hahn, D., Minola, T. and Eddleston, K.A. (2019), "How do scientists contribute to the performance of innovative start-ups? An imprinting perspective on open innovation", Journal of Management Studies, Vol. 56 No. 5, pp. 895-928.

Hoang, H. and Antoncic, B. (2002), "Network-based research in entrepreneurship", Journal of Business Venturing, Vol. 18 No. 2, pp. 165-187, doi: 10.1016/S0883-9026(02)00081-2.

Hoang, H. and Antoncic, B. (2003), "Network-based research in entrepreneurship", Journal of Business Venturing, Vol. 18 No. 2, pp. 165-187, doi: 10.1016/S0883-9026(02)00081-2.

Holm, D.B., Eriksson, K. and Johanson, J. (1999), "Creating value through mutual commitment to business network relationships", Strategic Management Journal, Vol. 20 No. 5, pp. 467-486, doi: $10.2307 / 3094165$.

Iansiti, M. and Levien, R. (2004), "Strategy as ecology”, Harvard Business Review, Vol. 82 No. 3, p. 68, doi: 10.1108/eb025570.

Isenberg, D.J. (2010), "How to start an entrepreneurial revolution", Harvard Business Review, (June), Vol. 12, doi: 10.1353/abr.2012.0147.

Isenberg, D.J. (2011), "The entrepreneurship ecosystem strategy as a new paradigm for economic policy", in paper presented at the Institute of International European Affairs, Principles for Cultivating Entrepreneurship, Dublin, Vol. 1 No. 781.

Jansen, H. (2010), "The logic of qualitative survey research and its position in the field of social research methods", in Forum Qualitative Sozialforschung/Forum: Qualitative Social Research, Vol. 11, No. 2.

Jarillo, J.C. (1988), “On strategic networks”, Strategic Management Journal, Vol. 9 No. 1, pp. 31-41, doi: $10.1002 /$ smj.4250090104.

Jocevski, M., Arvidsson, N. and Ghezzi, A. (2020), "Interconnected business models: present debates and future agenda", Journal of Business and Industrial Marketing, Vol. 35 No. 6, pp. 1051-1067, doi: 10.1108/JBIM-06-2019-0292.

Jung, K., Eun, J.H. and Lee, S.H. (2017), "Exploring competing perspectives on government-driven entrepreneurial ecosystems: lessons from Centres for Creative Economy and Innovation (CCEI) of South Korea”, European Planning Studies, Vol. 25 No. 5, pp. 827-847.

Khanna, T., Gulati, R. and Nohria, N. (1998), "The dynamics of learning alliances", Strategic Management Journal, Vol. 19 No. 3, pp. 193-210.

Liguori, E., Bendickson, J., Solomon, S. and McDowell, W.C. (2019), "Development of a multidimensional measure for assessing entrepreneurial ecosystems”, Entrepreneurship and Regional Development, Vol. 31 Nos 1-2, pp. 7-21.

Massa, L. and Tucci, C.L. (2013), "Business model innovation", The Oxford Handbook of Innovation Management, Vol. 20 No. 18, pp. 420-441.

Mody, A. (1993), "Learning through alliances", Journal of Economic Behavior and Organization, Vol. 20 No. 2, pp. 151-170.

Moore, J.F. (1993), "Predators and prey: a new ecology of competition", Harvard Business Review, Vol. 71 No. 3, pp. $75-86$.

Nambisan, S. (2017), "Digital entrepreneurship: toward a digital technology perspective of entrepreneurship", Entrepreneurship: Theory and Practice, Vol. 41 No. 6, pp. 1029-1055. 
Neck, H.M., Meyer, G.D., Cohen, B. and Corbett, a C. (2004), "An entrepreneurial system view of new venture creation”, Journal of Small Business Management, Vol. 42 No. 2, pp. 190-208, doi: 10. 1111/j.1540-627X.2004.00105.x.

Peppard, J. and Rylander, A. (2006), "From value chain to value network: insights for mobile operators", European Management Journal, Vol. 24 Nos 2-3, pp. 128-141.

Pitelis, C. (2012), "Clusters, entrepreneurial ecosystem co-creation, and appropriability: a conceptual framework", Industrial and Corporate Change, Vol. 21 No. 6, pp. 1359-1388, doi: 10.1093/icc/ dts008.

Porter, M.E. (1980), "Industry structure and competitive strategy: keys to profitability", Financial Analysts Journal, Vol. 36 No. 4, pp. 30-41.

Porter, M.E. (1996), "Competitive advantage, agglomeration economies, and regional policy", International Regional Science Review, Vol. 19 Nos 1-2, pp. 85-90.

Roundy, P.T., Brockman, B.K. and Bradshaw, M. (2017), "The resilience of entrepreneurial ecosystems", Journal of Business Venturing Insights, Vol. 8, pp. 99-104.

Sandberg, W.R. (2003), "Note to instructors case study: roustam Tariko: Russian entrepreneur", Entrepreneurship: Theory and Practice, Vol. 27 No. 3, pp. 315-318.

Sassanelli, C., Pezzotta, G., Pirola, F., Sala, R., Margarito, A., Lazoi, M., ... and Terzi, S. (2018), "Using design rules to guide the PSS design in an engineering platform based on the product service lifecycle management paradigm”, International Journal of Product Lifecycle Management, Vol. 11 No. 2, pp. 91-115.

Secundo, G., Mele, G., Sansone, G. and Paolucci, E. (2020), "Entrepreneurship education centres in universities: evidence and insights from Italian 'contamination lab' cases", International Journal of Entrepreneurial Behavior and Research, Vol. 26 No. 6, pp. 1311-1333.

Shafer, S.M., Smith, H.J. and Linder, J.C. (2005), "The power of business models”, Business Horizons, Vol. 48 No. 3, pp. 199-207, doi: 10.1016/j.bushor.2004.10.014.

Shane, S. and Venkataraman, S. (2000), "The promise of entrepreneurship as a field of research", Academy of Management Review, Vol. 25 No. 1, pp. 217-226.

Spigel, B. and Harrison, R. (2018), "Toward a process theory of entrepreneurial ecosystems", Strategic Entrepreneurship Journal, Vol. 12 No. 1, pp. 151-168.

Spigel, B. (2017), "The relational organization of entrepreneurial ecosystems", Entrepreneurship: Theory and Practice, Vol. 41 No. 1, pp. 49-72.

Stam, E. (2015), "Entrepreneurial ecosystems and regional policy: a sympathetic critique", European Planning Studies, Vol. 23 No. 9, pp. 1759-1769.

Tastle, W.J. and Wierman, M.J. (2007), "Consensus and dissention: a measure of ordinal dispersion", International Journal of Approximate Reasoning, Vol. 45 No. 3, pp. 531-545.

Walker, G., Kogut, B. and Shan, W. (1997), "Social capital, structural holes and the formation of an industry network", Organization Science, Vol. 8 No. 2, pp. 109-125.

Wild, J. (2009), "Intangible values collapse-the old $70 \%$ to $80 \%$ claim is now officially dead and buried||", Intangible Asset Magazine, Vol. 24.

Yin, R.K. (2009), Case Study Research: Design and Methods, 5th ed., Sage Publications, London.

\section{About the authors}

Angelo Cavallo, Ph.D. is Assistant Professor at Politecnico di Milano. His main research areas include Strategic Management, Entrepreneurship and Digital Transformation. His research interests are focused on entrepreneurial ecosystems, entrepreneurial dynamics and business modeling. He is member of the core faculty of MIP - Graduate School of Business and Director of the Space Economy Observatory at Politecnico di Milano. He is author of journal articles (appearing in outlets such as Journal of Business Research, Technological Forecasting and Social Change and the International Entrepreneurship and Management Journal), book chapters and conference proceedings. Angelo Cavallo is the corresponding author and can be contacted at: angelo.cavallo@polimi.it 
JSBED

28,2

276

Antonio Ghezzi, Ph.D. is Associate Professor of Strategy and Entrepreneurship at the Department of Management, Economics and Industrial Engineering - Politecnico di Milano. His main research field is strategy, entrepreneurship and digital transformation, with a focus on startups' business model design, innovation and validation. He is author of more than 100 refereed journal articles (appearing in outlets such as, International Journal of Management Reviews, Technological Forecasting and Social Change and Journal of Business Research and R\&D Management), books, book chapters and conference proceedings.

Silvia Sanasi is a Ph.D. Candidate in strategic management, innovation and entrepreneurship at the School of Management of Politecnico di Milano, where she also collaborates as a researcher in the HiTech Startups and Startup Intelligence Observatories. Her research interests encompass experimentation in business model design, innovation, validation and scaling, as well as the strategic implications of innovation management and digital platforms.

For instructions on how to order reprints of this article, please visit our website: www.emeraldgrouppublishing.com/licensing/reprints.htm Or contact us for further details: permissions@emeraldinsight.com 